\section{Absorption Spectra of Some Metallic Vapours.}

In the course of our experiments on the absorption of light by vapours of different metals, we have recently photographed the absorption spectra of lead, bismuth, antimony, thallium, and magnesium with the following results :

(I) The absorption spectrum of lead shows at $1100^{\circ} \mathrm{C}$., besides the fundamental line 2833 and some other lines, a faint banded spectrum which has not been described previously. These bands extend from $\lambda_{3000}$ to $\lambda_{3320} \AA$.U. The interval between the various bands is nearly constant and is equal to $32 \AA$.U.

(2) The absorption spectrum of bismuth shows besides the "raie ultime" 3067, a typical banded spectrum containing about twenty bands. The absorption at each of these bands is very diffuse and complex, consisting of a number of fine bands. With increase of vapour density all the bands gradually fuse together (beginning from the short wave-length side) to form a region of continuous absorption.

(3) The absorption spectrum of antimony shows a fine line and a banded spectrum on the short wavelength side of this line, which has not been described previously. The fine line is at $\lambda 2310$, and the bands extend from $\lambda_{23} 0_{4}$ to $\lambda 2200$, with a constant interval of I5 A.U. nearly. Eight of these bands have been photographed.

(4) A long column of non-luminous vapour of magnesium is found to absorb, besides the line $285^{2}$, $\lambda_{457} \mathrm{I}$, the single line spectrum of the element.

(5) The absorption spectrum of the non-luminous vapour of thallium shows at high temperatures, besides the lines of sharp and diffuse series, some prominent bands and lines due probably to $\mathrm{Tl}_{2}$ molecules. A study of anomalous dispersion of the vapour by the method of Kundt's crossed prisms showed that at $\lambda_{3775}$ there is anomalous dispersion and that at $5350 \cdot 6$ the phenomenon is much weaker.

A detailed account of these experiments together with the photographs of the absorption spectra will be published shortly.
A. L. NARAYAN.
G. Subrahmaniam.
D. Gunnatya.
K. Rangadhamarao.

Research Laboratories,

\section{H.H. The Maharajah's College, Vizianagaram.}

\section{The Theory of Hearing.}

To the letters of Sir R. A. S. Paget and Mr. Wilkinson in NATURE of July I9 I will reply in regard to the piano experiment by saying that what a person hears is chiefly what he expects to hear. A conspicuous example is that of hearing the tones in whispered vowels. Every observer hears a different system. In the piano experiment I can hear fairly good vowels for $a h$ and oo when sung; otherwise the result is vague. Yet in speech I hear every minute shading. I am quite in agreement with these gentlemen and most other writers in believing that the vowels are characterised by tones of definite pitch, but that is a matter that cannot be established by any such method.

The portamento piano experiment, however, furnishes a definite proof that the ear is not a resonating organ. When a tone is sung into the piano portamento all the strings vibrate more or less, and the result is a complete jangle. Exactly the same result would occur if the ear were a resonating organ. Much singing and all speech is portamento. If the basilar membrane acted by resonance, the voice of the singer would usually be a jangle with no pitch, and for the melody of speech we would have only a confused noise. This is exactly what I pointed out in my original letter to NATURE, April 22, 1922. The piano as a resonating organ responds to portamento singing by a perfect jangle. That the ear responds by a sensation of a clear rising or falling tone is a quite adequate proof that it does not possess a resonating organ. This ought to settle the matter for good from the physical point of view. To those of us who are accustomed to work with delicate human tissues the Helmholtz resonance theory is simply unthinkable.

The resonance theory is dead and there is no use in wasting time in trying to put life into it again. The deformation theory, as explained in NATURE for April 26 , rests on distinct theses in strict accordance with anatomical and physiological facts, not one of which has been called in question.

University of Vienna.

$$
\text { E. W. SCripture. }
$$

\section{Germanium and its Derivatives.}

UNTIL recently, germanium was regarded as one of the rarest of metals, but recent discoveries of larger sources of its minerals lend interest to any possible applications of this element. Germanium dioxide is appreciably soluble in water and an aqueous solution of a concentration of one in 5000 has a marked inhibitory action on the growth of Bacillus coli communis.

So far little is known concerning the organic derivatives of germanium which we are now investigating (Chem. Soc. Trans., I924, I25, I261). With the aid of the Grignard reaction, germanium halides have furnished germanium tetraphenyl, germanium triphenyl bromide and oxide, and hexaphenyldigermane. Water-soluble organic derivatives of germanium have also been obtained which are now under examination in this laboratory.

$$
\begin{aligned}
& \text { G. T. MORGAN. } \\
& \text { H. D. K. Drew. }
\end{aligned}
$$

The University,

Edgbaston, Birmingham, July I 8.

\section{Mathematics at British Universities.}

A LiT'Tle time ago I turned light-heartedly to the study of relativity. I had no doubt of the sufficiency of my equipment for such study because two British universities had found me worthy of a degree in mathematics. You can imagine my surprise when I found how little connexion the mathematics of relativity had with my university studies, and what a serious study of new subjects I must undertake. Chief among the new subjects is vector analysis or tensor calculus, and I am puzzled that so many continental writers (as well as a few in this country) show a command of vector analysis, while my two universities knew nothing of it.

It is, however, some years since I left these universities, and it may be that vector analysis has now attained an appropriate position there. It is on this point that I hope your readers may help me by telling me which universities include vector analysis in their courses, and by indicating how far they go in this and other subjects preparatory to relativity. In this inquiry I am not actuated by mere curiosity. I am anxious to know, and I am sure many of your readers also wish to know, whether the teaching of mathematics in our universities is abreast of the times. I hope, therefore, that some one at Cambridge will say what is being done there, or if Cambridge is doing nothing, I hope some one elsewhere will be able to show that his university is making good the omission of Cambridge.

A Beginner in Relativity.

NO. 2858 , VOL. I I 4 ] 